\title{
Theoretical Basis on English Translation for Chinese Cultural Classics
}

\section{Fenghua Li}

Teaching and Research Institute of Foreign Languages, Bohai University, Jinzhou, 121013, China

Izy8917891@163.com

Keywords: Chinese cultural classics; English translation; theoretical basis; context theory; multi system theory; functional equivalence theory

\begin{abstract}
As the lack of the awareness of building translation theory and the insufficiency of research on translation theory, the study on translation theory lags behind the achievements obtained in the field of practical translation, especially in Chinese classics translation field. In this paper, we focus on context theory, multisystem theory and functional equivalence theory in the field of translation. Specifically, context theory requires the translator to take specific context into account; multisystem theory requires to consider the translation in a broader field of cultural activities directly; functional equivalence theory requires to achieve functional equivalence between two languages rather than rigid correspondence. The research results from this paper enrich and develop the translation theory and it is meaningful for improving the level of Chinese cultural classics translation.
\end{abstract}

\section{Introduction}

With the strengthening of globalization trend, there are more and more contacts and communication among the countries all over the world. In the process of communication, people can feel and experience different national and regional cultures. It can not only be helpful for spreading our national culture, but also be beneficial for filling the vacancy by foreign culture. Under the background of globalization, the cultural contact and communication among countries vary from spontaneous to conscious, from passive to active, from one-way to two-way, from hegemony to equality. The appearance of classics is the result of the academic development. It is also a historical process from the development of the ideology and the history of important books and literature written in words. The five thousand years of civilization of the Chinese nation is carrying Chinese civilization great contributions to world civilization. Chinese civilization and Chinese culture have a long, extensive and profound history of Chinese characters. The Chinese classics which are reserved in Chinese characters have attracted worldwide attention and it is also the spiritual wealth of mankind. Translation texts in Chinese culture, play an important role in promoting world cultural exchanges. Translation has long been subjected to the existence of the so-called translation theories, and the discussion of the function of guidance for practice. Translation is no longer a borderline subject, but a comprehensive strong discipline. It gains widely attention from the research fruits of related disciplines, and becomes the important condition of perfecting related discipline. In recent years, translation theory has some development, but still not completely forms scientific theories, especially in the field of translation texts. This article will solve the problem of translation which has been debated, and provide practical guidelines and rules for Chinese cultural classics works translation.

\section{Context Theory}

Context is speech environment, including language factors and non-verbal factors. The words, such as context, time, space, scene, object, discourse premise are all contextual factors. From the perspective of linguistics, context is the subjective factors which are depended on a variety of show the rhetoric context in understanding and use of language in language communication. The most basic functions of context is restriction function and interpretation function, and is realized in certain conditions. Context itself sympathetic degree, association degree, the main body of 
background knowledge, the ability to search and context are the basic conditions in context functions.

Context can be divided into language context and non-linguistic knowledge context. The language knowledge context includes the use of language knowledge and understanding of the language context. Outside the language knowledge context, there are situational knowledge and background knowledge. Situational knowledge contains the communication activities of the time and place, the topic of communication, the degree of formal communication, and the relationship of the participants. Background knowledge includes the specific culture of social norms, rules of the session, general knowledge about the objective world, and how the participants get to know each other. As shown in Fig. 1 [1].

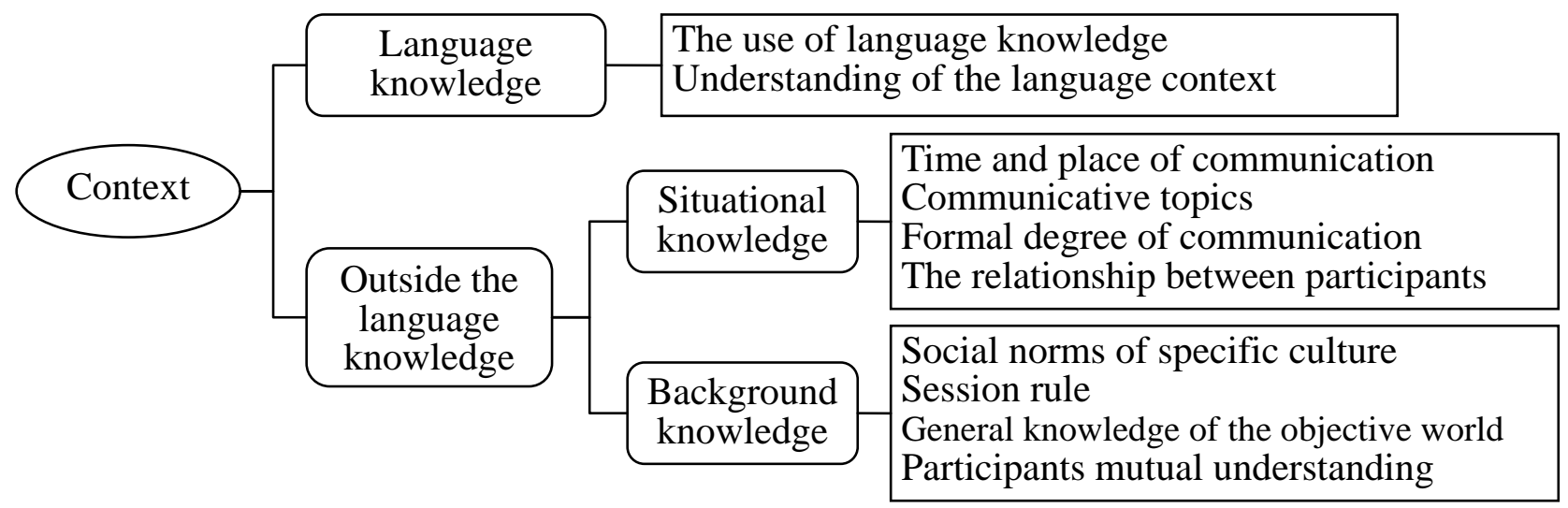

Fig. 1. Context includes knowledge

Cultural difference is another important effect on translation context. Contextual culture comes from background, including personal cultural background, special experience and individual psychological background. In the language of one culture, if the creation of discourse meanings of context dependence degree is higher, while the dependence of used language is relatively low, thus this culture is high context culture; On the contrary, if the dependence of meaning of the words to be used is relatively high, but the dependence on context is lower, then this kind of culture belongs to low context culture [2]. Difference between high and low cultural context is shown in Table 1.

Table 1. High and low context culture difference

\begin{tabular}{c|c}
\hline High context culture & Low context culture \\
\hline Hidden and implicit & Explicit and clear \\
\hline Suggestive information & Express information \\
\hline More non language encoding & More language encoding \\
\hline Reaction is rarely exposed & Reaction to the leakage \\
\hline Internal external difference & Internal external flexible \\
\hline Interpersonal relationship is close & Interpersonal relationship is not close \\
\hline High commitment & Low commitment \\
\hline Highly flexible time processing & Highly organized time \\
\hline
\end{tabular}

Translation transmits the language message in the context of a specific situation to the receivers by the code accurately. It is a kind of cross-language and cross-cultural communicative behavior, from "information decoding (source language)" to "information encoding (target language)" to "information to decode (target language)", including four stages of translation: comprehension, expression, inspection and receival [3]. To understand the process, the translator should give full consideration to the specific context factors of the original classics. Chinese and English, are two languages belonged to different language families. There is a very big difference between the cultural background and grammatical structure. Translation can't be completely to translated directly. You have to consider the original national culture and language text. Translators are 
required to fully understand the words with the cultural connotation, and combine with the corresponding cultural background. In this way the original language style, the language form and the artistic features can be kept [4].

\section{Multi System Theory}

Multi-system is regarded as a heterogeneous, open multiple system polymers. To be more specific, the system interaction is able to prompt internal continuous dynamic evolution process in the multivariate system. That is to say, the pluralistic system is a composed of many interrelated stratified factors, when these factors interact with each other, the polymers will change and vary. Multi-system theory is proposed by Itamar Even Zohar. In the early 70s, when he studied the Israeli Hebrew literature model, based on Russian formalism and Czech structuralism, he put forward a kind of common culture theory [5,6]. Itamar polysystem theory belongs to the dynamic functionalism, emphasizes the historical continuum and the complexity, openness and flexibility of the cultural system. Phenomenon of multiple system theory analyses the connection between various factors in the system and its surrounding closely related factors, and its value also depends on its position in the system network.

The core content of multiple systems theory is the "phenomenon of various social symbols. Specifically, it is dominated by various symbolic form of human communication, such as language, literature, economy, politics, ideology, etc.. That can be reviewd as a system of elements, rather than the irrelevant systems. These systems have different but interdependent behaviors, and run as an organized entity". But in this entity, " the status of each system is not equal, some are in the center, some are at the margins [7]. At the same time, the position is not invariable, every system in the whole organisation will continue to change through the endless struggle: the system in the center may be banished to the edge, and the system at the edge can capture the centre position."

Multi-systems theory broke through the limitations on a single text, static, isolated synchronic research methods to measure success or failure in the early period of translation study, translation and research on the larger cultural environment to dynamic and system research, update the understanding of translation studies, expand the study of contemporary translation horizons, have pioneering significance to translation studies. Traditional translation study is based on the original text as the center, focus on "how to translate", "how to faithfully", and "how to peer", and the standard of translation problems, don't too concerned about the "external political" choice of translation, the translation process and the influence of translation strategies, etc. To study, literary translation from the perspective of multiple system will recognize the literary translation and the target language culture system factors exist complex associated cultural behaviors. Translated literature coexist system, such as politics, ideology, literature, economy and so on, restricts the choice of translated texts, affecting the formation of translation criterion and translation literature library, determines the translation literary system in multicultural system operating mode, the position and role. So you will have a culture of translation phenomena in translation, context, literature and language, society, economy, politics, ideology, etc. Theory of multiple system "will direct translation study in wider cultural activities", "translation and broader social and cultural practices and processes, making it the more exciting object of study, and promote the" cultural turn "in translation studies. Theory of multiple system "for translation studies scholars not only opens up a new way", and, more importantly, "change the nature of the analysis of the translation, and expand the field of translation studies", and "improve the academic status of translation".

Multiple systems theory provides multiple entry points for the literature translation study for the translation of literature paper, and the evaluation makes a reasonable explanation on some phenomena. Multiple system theory of the translation of literary people from a new perspective on the "adequacy" in literary translation. From the literature translation in literature the pluralistic system of position this perspective to explain the phenomenon, lead on the position of the translated literature of translation norms, behavior patterns, the influence of the translation strategies. Multiple systems theory to translation studies, therefore, the introduction of cultural study way, the translation of culture, social condition and reading, politics, and many other factors combined, 
opens up a vast field of study for translation study. But multiple systems theory to the interpretation of the literary translation, there are "no sufficiency", rooted in the following several aspects [8]: emphasize the mainstream ideology, neglect the mainstream ideology, thus the rich translation phenomenon simplification; Too much emphasis on ideology determinism, ignored the principle of literary development and the subjectivity of the translator, motility and advanced; Too much emphasis on the poles, ignore the middle, as a result, the research methods of rigid, simplification, ignoring the influence of cultural factors on translation between the poles. Multiple systems theory to translation studies has opened up a descriptive, geared to the needs of the target language system, functional, system, the new way of dynamic, promote the cultural turn in translation studies, to broaden the field of translation studies. But this theory also exists limitations, it is also need to pay special attention to the problems in the translation process.

\section{Functional Equivalence Theory}

Functional equivalence theory is put forward by Eugene Nida, an American person. The main academic activities in his life revolves around the Bible translation. In the process of translation, to make the conversion between source language and target language have a standard, reduce differences, he developed a set of translation theories and eventually become one of the classic translation study. Core concept is "functional equivalence", when translated, it is required not to be rigid on the surface of the text but to achieve functional equivalence between two languages. In the process of translation, not only to achieve the equivalence of vocabulary, but also to cover the meaning, style and stylistic equivalence. The messages translated contain not just surface lexical information but also the deep cultural information, including words equivalence, syntactical equivalence, chapter equivalence and stylistic equivalence. In literary translation, the translator should take the principle of the four aspects of functional equivalence as a translation, accurately reproduce the source language in the target language culture connotation.

In order to accurately reproduce the source language culture and eliminate the cultural differences, the translator can follow these three steps [9]. The first step, striving to create both the original semantics and the original cultural characteristics of translation. Because these two languages stand for the two kinds of completely different cultures. Cultures may have similar factors, but they can't be completely the same. Therefore, it is impossible to achieve perfect translation and fully show the original cultural connotation. The translator can only reproduce the source language to the maximum extent; Secondly, if it cannot be considered for both meaning and culture, the translator only part with formal equivalence, in the process of translation by changing the form of the original, to reproduce the original semantics and cultural purposes. Sometimes the translator can be eliminated by changing the words in the form of a cultural differences. Thirdly, if the change of the form is still not enough to express the original semantics and culture, then a "hit" can be used in the translation skills to solve the cultural differences to make the source language and target language in the sense of equivalence. "Hit" refers to the deep structure of the source language into the target language of surface structure, and the cultural connotation of the source language article is illustrated with the vocabulary of the target language and instructions. The connotation of the original is not expressed on the surface of the lexical meaning, but hidden in between the lines.

The traditional translation method transmits the original language structure to the target language structure through the intermediary linguistics, which is shown in Fig. 2(a). Nida claims traditional translation method is not perfect because it is difficult to achieve functional equivalence. Thus he puts forward the "three-step translation method", named "analysis - transform - restructuring", as shown in Fig. 2(b) [10]. In Nida's translation mode, first of all, the translators analyse primitive surface structure, and turn it into core information; Then, express the core information in the target language form; Finally, translators choose the most proper way to use the target language structure which readers can easily understand to express the original content.

Culture plays an important role in the process of translation. Different ethnic groups belong to different cultural systems, there is a very big difference among their geographical environment, 
historical conditions, social background. Thus the way of life, the way of thinking, cultural tradition, aesthetic habit will be completely different in many ways. Based on the functional equivalence theory, when translate Chinese cultural classics, translators should pay attention to the following cultural factors [11]: (1) the historical factors, language development is affected by national historical development directly. For foreigners, those associated with historical tradition of Chinese culture is hard to understand, so the translation should take the initiative to solve the problem; (2) the religious factors, religion has had a huge impact on people's lives. Buddhism and Taoism are prevalent in China, but in many english-speaking countries, they believe in Christian, therefore translation related to religious project occurs; (3) the living environment and life experience factors, different countries have different living environment and life experience, the difference will be reflected in their own language; (4) social development factors, in recent years, Chinese society has experienced great changes in the political, economic and cultural. Many new things emerge and become a part of the social life, thus contribute to the enormous influence on language and culture.

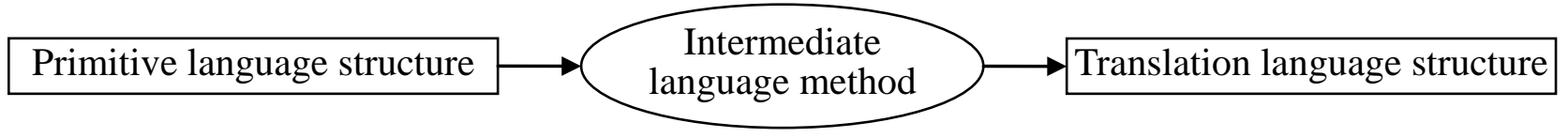

(a) Traditional translation mode

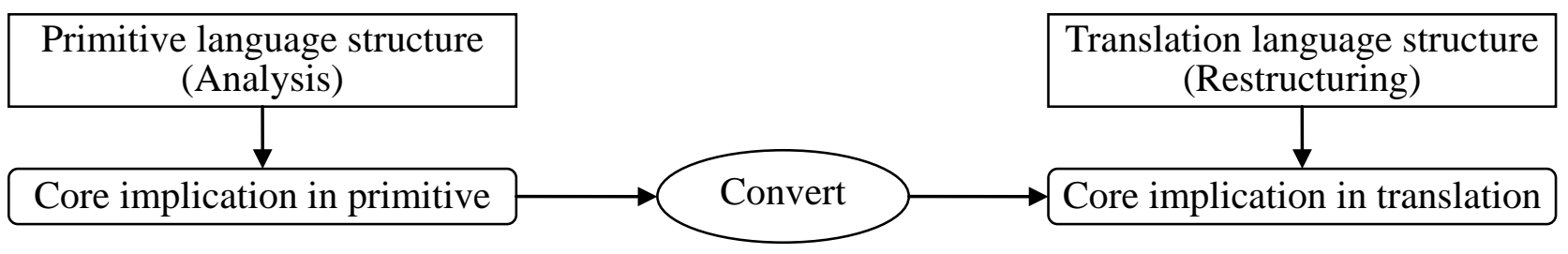

(b) Nida translation model

Fig. 2. Traditional translation mode and Nida translation model

\section{Conclusion}

Translation research, as an interdisciplinary field of study, attracts more and more attention from scholars. On the one hand, it can absorb the research achievements of related disciplines, on the other hand, it is helpful to promote the perfection and development of relevant subject and then become a comprehensive research subject. But as the result of the lack of awareness, and insufficiency of the research about theoretical translation construction and translation practice, the related research achievements in this field stay at the surface. As a whole, translation theory research lags behind the achievements which are obtained in the field of translation practice, especially in Chinese classics translation field. Translation has both a strong theoretical property and the practical connotation. There is a dialectical relationship between translation theory and the practice. Translation theory is produced from the translation practice and in turn guide the practice. However, practice can enrich the translation theory. If there is no translation theory to guide the practice, translation practice will detour. Therefore, we should not only focus on translation theory study, but strengthen the translation practice. The results of this paper can enrich and develop the theory of translation and it is of great significance to improve the translation level of Chinese cultural classics. 


\section{Acknowledgement}

This work is supported by social science fund project of Liaoning province (L15BWW004): Improving the Strategy of English Translation Level for Chinese Cultural Classics.

\section{References}

[1] X. W. Hu, "A Review on Context Theory," Master's degree of Anhui University, 2012.

[2] D. Y. Meng, F. Zhao, "A contrastive study of communication patterns in high and low context cultural," Journal of Shanxi Agricultural University (Social Science Edition), vol. 12, no. 10, pp. 1284-1287, 2011.

[3] R. Ma, "Context and translation in the context of relevant context theory," Journal of Lanzhou Institute of Education, vol. 30, no. 1, pp. 133-135, 2014.

[4] J. M. Lai, "A study of translation strategies from the perspective of context theory," Modern Communication, vol. 29, no. 6, pp. 56, 2015.

[5] M. J. Cha, "On the Integration of Polysystem Theories and Its Contribution to the Development of the Studies of Translated Literature History," Journal of Shanghai University (Social Sciences Edition), vol. 32, no. 2, pp. 126-140, 2015.

[6] J. N. Meng, "Comment on the influence of Zohar polysystem theory on literary translation strategy," Journal of Mudanjiang College of Education, vol. 32, no. 4, pp. 27-28, 2014.

[7] X. Y. Cao, "On multi system theory and Chinese Translation Studies," Young \& World, vol. 61, no. 4, pp. 165-166, 2012.

[8] P. Lin, "Contributions and Limitations: A Critical Review of Polysystem Theory," Journal of Chongqing University of Technology (Social Science), vol. 27, no. 1, pp. 103-106, 2013.

[9] Interactive Encyclopedia, "Functional theory," http://www.baike.com/wiki/FunctionalEquivalenceTheory, 2015-10-20.

[10] L. H. Wang, Y. T. Shi, "The Application of Nida's Functional Equivalence Theory in Literature Translation: Based on the Translation Practice of The Literature of Modern Saudi Arabia," Foreign Language and Literature, vol. 30, no. 4, pp. 123-126, 2014.

[11] Y. K. Bu, X. L. Wang, "Applying Functional Equivalence in Translating Chinese Culture Specific Items into English," Journal of Northeast Normal University (Philosophy and Social Sciences)n, vol. 59, no. 1, pp. 85-89, 2009. 